\title{
ALEXANDRIA
}

Revista de Educação em Ciência e Tecnologia

ALEXANDRIA

\section{Sobre a Pesquisa-Ação nas Dissertações e Teses em Ensino de Biologia (1972-2011)}

\author{
About Action-Research in Dissertations and Theses in Teaching \\ Biology (1972-2011)
}

Paulo Marcelo Marini Teixeira ${ }^{a}$; Jorge Megid Neto ${ }^{b}$

a Departamento de Ciências Biológicas, Universidade Estadual do Sudoeste da Bahia, Jequié, Brasil - pmarcelo@uesb.edu.br b Faculdade de Educação, Universidade Estadual de Campinas, Campinas, Brasil - jmegid@ gmail.com

Palavras-chave: Produção acadêmica. Pesquisa-ação. Ensino de biologia.

\section{Keywords:}

Dissertations. Thesis.

Action-research.

Teaching of biology.
Resumo: O artigo analisa um estrato da produção acadêmica expressa em dissertações e teses em Ensino de Biologia, defendidas no período 1972-2011, em programas de pós-graduação brasileiros. A partir da identificação de 1000 documentos, todos direta ou indiretamente relacionados à referida subárea da pesquisa em Educação em Ciências, foram selecionados apenas aqueles que empregaram em seus títulos, resumos e/ou palavras-chave o termo Pesquisa-Ação como designação para a modalidade de investigação realizada. Com esse procedimento detectamos 24 documentos que foram analisados por meio da técnica de análise de conteúdo. Como parte da análise, as informações relativas ao delineamento metodológico desses trabalhos foram cotejadas com um conjunto de critérios utilizados para definirmos pesquisa-ação, segundo a literatura dedicada especificamente a essa modalidade investigativa. Os resultados apontam o baixo número de pesquisas dessa natureza na produção acadêmica investigada, confirmando as observações encontradas na literatura especializada que indicam a confusão generalizada a envolver o emprego do slogan "pesquisa-ação".

Abstract: The article analyzes a segment of the academic production expressed in dissertations and theses in Teaching of Biology, defended in the period 1972-2011, in Brazilian graduate programs. We have identified 1000 documents related to this subarea of Science Education research. In the sequence, only those that used the term Action-Research as a designation for the research modality were selected in their titles, abstracts and / or keywords. We detected 24 documents that were analyzed through the technique of content analysis. As part of the analysis, the information regarding the methodological design of these works was compared with a set of criteria used to define action-research, according to the literature dedicated specifically to this research modality. The results point to the low number of researches of this nature in the academic production investigated, confirming observations found in the specialized literature, showing the general confusion that involves the use of the slogan "action research". 


\section{Introdução}

Pesquisa-Ação é uma modalidade investigativa amplamente conhecida no conjunto da comunidade de pesquisadores das áreas de Educação e Educação em Ciências (EC). Entretanto, é bom lembrar que o fato de termos contato com o termo e até empregá-lo em nossos trabalhos, em alguns momentos, nem sempre significa compreensão precisa do perfil que projetos de pesquisa-ação deveriam assumir, sobretudo se levarmos em conta as indicações disponíveis na literatura específica sobre essa temática.

Quando buscamos informações sobre pesquisa-ação, considerando, principalmente, o campo das pesquisas educacionais, nos deparamos com uma abundante literatura. Tal fato parece ser resultado da confluência de pelo menos dois fatores: o aumento da popularidade e do emprego das modalidades de investigação que articulam ação e pesquisa (EL ANDALOUSSI, 2004; TRIPP, 2005; ZEICHNER; DINIZ-PEREIRA, 2005; THIOLLENT, 2011); e os discursos, cada vez mais incisivos, fomentando a tendência para que os pesquisadores ofereçam respostas para problemas práticos e funcionais, e que os resultados de suas pesquisas tenham influxo, de preferência, imediato, na prática e na melhoria das condições de ensino e aprendizagem em nossas escolas (GATTI, 2000; ANDRÉ, 2006; MIRANDA; RESENDE, 2006).

Temos que observar também que o crescimento do movimento em prol da realização das chamadas pesquisas-ações, gerou um outro fenômeno interessante, qual seja, a pluralidade de terminologias utilizadas por pesquisadores, educadores e especialistas na área de metodologia de pesquisa e do trabalho científico para se referir a esse conjunto de processos investigativos. É neste sentido que encontramos o emprego dos slogans pesquisa-ação, investigação-ação, pesquisa colaborativa, ação-pesquisa, pesquisa participante, pesquisa participativa, pesquisas ativas, pesquisa de intervenção, etc.

Neste último aspecto, em particular, quando focalizamos pesquisas educacionais, há amplo espectro de denominações, por vezes, empregadas livremente, de forma vaga e sem o devido cuidado, fato que, a nosso ver, cria um quadro de confusão generalizada (TRIPP, 2005), ou como diria Chizzotti (2006), uma espécie de sincretismo ambíguo; ou ainda um mosaico (FRANCO, 2005; MIRANDA; RESENDE, 2006; BARBIER, 2007), em que detectamos a utilização livre de certas definições e rótulos, sem a devida atenção com os pressupostos epistemológicos, teóricos e metodológicos, além de concepções de mundo e de educação que deveriam sustentar nossas escolhas quando desenvolvemos qualquer trabalho de pesquisa (FRANCO, 2005; CHIZZOTTI, 2006; GHEDIN; FRANCO, 2008).

Como assinala El Andaloussi (2004, p. 101), a confusão conceitual em torno da pesquisa-ação "não ajuda a construir uma definição clara e operacional" dessa modalidade de investigação. Adicionalmente, não podemos ignorar o fato de que essa multiplicidade de 
denominações traduz, em certo sentido, "opções ora diferentes e convergentes, ora desiguais ou mesmo divergentes" (BRANDÃO, 2006, p. 34). Portanto, o problema não se refere somente à questão do emprego deste ou daquele termo; não é uma simples questão de nomenclatura, ou mesmo, sobre quem detém o monopólio para prescrever a "verdadeira" pesquisa-ação. Quando consultamos a literatura dedicada às questões metodológicas de pesquisa, sobretudo centrando foco nos autores consagrados na discussão dessas modalidades investigativas, detectamos diferenças marcantes entre a pesquisa-ação e as outras modalidades de pesquisas de natureza interventiva, a exemplo das pesquisas experimentais, pesquisas de intervenção, pesquisa participante, etc.

A nosso ver, a adoção genérica do termo esconde outras facetas alusivas à fragilidade metodológica que caracteriza parte dos trabalhos e estudos acadêmicos desenvolvidos na área educacional. É por isso que vale a pena investir esforços no trabalho de aprimoramento conceitual, evitando o uso de conceitos vagos, genéricos e flexíveis em demasia. A precisão nos conceitos utilizados dentro de um determinado campo de pesquisa, e o trabalho realizado neste sentido, deveriam fazer parte, de um processo mais amplo que envolve a própria consolidação de nossos referenciais teórico-metodológicos, isto é, é um processo inerente ao movimento em direção à consolidação e amadurecimento de nosso campo de pesquisa.

Neste artigo, a intenção é, em primeiro momento, sintetizar, do ponto de vista teórico, algumas ideias que colaboram para a construção de uma caracterização mais precisa do termo pesquisa-ação (PA) no contexto das pesquisas em Educação em Ciências. No segundo momento, digamos, na parte empírica do trabalho, envolvendo a explicitação de dados oriundos de investigação realizada, examinamos um estrato de dissertações e teses (DTs) em Ensino de Biologia, comparando esses estudos acadêmicos com uma matriz de critérios utilizados para identificação de pesquisas delineadas como pesquisa-ação.

\section{Elementos para uma conceituação de Pesquisa-Ação}

O primeiro ponto a observar é que literatura não traz quadro de homogeneidade quando pensamos na busca de definições e caracterizações para a PA. As diversas correntes encontradas passam pelo trabalho original de Kurt Lewin; pelas versões europeias, preocupadas com a questão do aprimoramento técnico dos práticos e com a análise institucional. Nos deparamos também com a vertente representada pelos autores australianos, com atenções direcionadas para a teoria crítica; e, por fim, algumas correntes LatinoAmericanas, buscando na pesquisa-ação e também na pesquisa participante, instrumentos de emancipação e transformação social (THIOLLENT, 1999; EL ANDALOUSSI, 2004; BARBIER, 2007). Uma definição relativamente simples pode ser formulada nos seguintes termos: “Trata-se de pesquisas nas quais há uma ação deliberada de transformação da 
realidade; pesquisas que possuem duplo objetivo: transformar a realidade e produzir conhecimentos relativos a essas transformações" (HUGON; SEIBEL apud BARBIER, 2007, p. 17, grifo nosso). Para Dionne (2007) existem muitas definições de PA, tanto que o autor menciona que poderíamos falar em "pesquisas-ações". Entretanto, ele identifica um aspecto comum entre elas: "a importância do vínculo que une os pesquisadores e os atores ou profissionais" (p. 44). A conceituação de PA mais utilizada pelo referido autor é a seguinte: “(...) prática que associa pesquisadores e atores em uma mesma estratégia de ação para modificar uma dada situação e uma estratégia de pesquisa para adquirir um conhecimento sistemático sobre a situação identificada" (p. 68).

É importante salientar que PA rejeita noções positivistas ligadas às ideias de neutralidade, objetividade e verdade. Assim, como modalidade de investigação, pressupõe a explicitação dos valores pessoais e práticos envolvidos no processo investigativo e que, dependendo de como for encarada, pode significar forma totalmente distinta para se conceber e desenvolver pesquisas em Ciências Humanas e Sociais (EL ANDALOUSSI, 2004; MORIN, 2004; BARBIER; 2007; FRANCO, 2005; GREENWOOD; LEVIN, 2006). Tal posição é definida a partir de forte crítica à prática científico-acadêmica ortodoxa, traduzindo-se em uma ruptura epistemológica em relação aos cânones da pesquisa tradicional. A perspectiva de crítica ao paradigma positivista problematiza diversos aspectos, alguns dos quais, relacionados às relações entre sujeito e objeto e, entre teorias e práticas; aos problemas associados a pressupostos ligados às noções de neutralidade, objetividade/subjetividade e de verdade na prática da pesquisa; além disso, valoriza-se o emprego de categorias interpretativas durante o processo de análise de dados e de geração do conhecimento científico e suas implicações para a prática social (CARR; KEMMIS, 1986; FRANCO, 2005; BARBIER, 2007).

Maria Amélia S. Franco menciona que a PA pode ser norteada por três dimensões: i) ontológica: referente à natureza do objeto a ser pesquisado. A PA busca conhecer a realidade objeto de interesse, foco da pesquisa, de forma a transformá-la; ii) metodológica: referente às relações entre sujeito-conhecimento. É neste sentido que notamos, com mais intensidade, a aversão das propostas de PA aos cânones positivistas, com a exigência de um mergulho na intersubjetividade que permeia o processo e os diversos participantes, uma relação de interação horizontal entre pesquisadores e demais sujeitos, e a recusa da neutralidade, apostando suas fichas numa perspectiva dialética de ação-reflexão; iii) epistemológica: referente aos processos de conhecimento utilizados pelos pesquisadores, o que implica a utilização de uma proposta metodológica e de ação articuladora de práticas dialógicas e participativas, flexíveis e ajustáveis ao longo de todo o processo, considerando as etapas de 
espirais cíclicas: planejamento, ação, reflexão, pesquisa, ressignificação, replanejamento, etc. (FRANCO, 2005, p. 489-491).

Adicionalmente, ainda em relação ao posicionamento epistemológico da PA, chamamos atenção para o seguinte aspecto: a referida incompatibilidade entre a PA e a pesquisa tradicional, inspirada em pressupostos positivistas, não pode significar desenvolver PA como uma espécie de investigação de segunda categoria, negligenciadora de padrões mínimos de coerência teórica, rigor e validade para o conhecimento obtido conforme critérios pactuados e exigidos dentro de um determinado campo de pesquisa. Assim, segundo Thiollent (2011, p. 26), o "grande desafio metodológico consiste em fundamentar a inserção da pesquisa-ação dentro de uma perspectiva de investigação científica, concebida de modo aberto e na qual a "ciência" não seja sinônimo de "positivismo", "funcionalismo" ou de outros "rótulos". Em consequência, PA não pode representar apenas ativismo ou, de outro modo, renunciar à construção de conhecimento sistematizado. Por isso, defendemos que a mediação teórico-conceitual-metodológica deve perpassar todas as etapas do projeto, de tal sorte que, pesquisa-ação não deveria significar a adoção de posturas anticientíficas, espontaneítas, imediatistas, dogmatistas, partidaristas e populistas (DEMO, 2004; DIONNE, 2007; THIOLLENT, 1999; 2011).

A maioria dos autores menciona a meta de transformação da realidade ou mudança social, na qual um projeto é desenvolvido, geralmente considerando situações sociais problemáticas (GHEDIN; FRANCO, 2008; BOGDAN; BIKLEN, 2010; THIOLLENT, 2011). Aliás, a categoria "mudança" parece ser nuclear quando se fala em PA, sobretudo no sentido de considerá-la "um processo de intervenção coletiva assumido por participantes práticos (praticiens), com vistas a realizar uma mudança social com a implicação dos atores em situação" (DIONNE, 2007, p. 24). Um problema neste ponto é que o alcance desse tipo de transformação e/ou mudança nem sempre é explicitado e, em tais casos, não fica claro se tais mudanças são projetadas mirando um plano micro, intermediário ou em macro escala. Por vezes, não fica evidente também a natureza da transformação desejada: podemos encontrar projetos em que se logram mudanças práticas, como diagnosticar e resolver problemas, aprimorar processos, mobilizar grupos para determinadas situações específicas de interesse, levar indivíduos e grupos a tomadas de posição, desencadear mudanças institucionais, etc. Em outros casos, a ideia de transformação pretendida é bem mais complexa, envolvendo processos de diagnóstico, análise e tomada de posição e ação em relação a problemas sociais mais amplos.

Deste modo, em função dessas intencionalidades, explícitas ou subentendidas, pelo menos duas variantes são claramente visualizadas. Em parte dos casos, a PA adota caráter crítico-emancipatório, em outra, talvez englobando as situações mais frequentes, centra-se em 
questões de natureza mais técnica, instrumental, prática ou pragmática. Com efeito, Thiollent (2011, p. 105) vislumbra basicamente essas duas possibilidades para a PA: uma de orientação crítico/emancipatória e outra de orientação pragmática. O autor caracteriza tais possibilidades da seguinte forma:

Na concepção das práticas educativas ou políticas, os partidários da PA adotam frequentemente uma orientação crítica, mais ou menos radical, voltada para a conscientização ou para a mobilização popular. Ao passo que, entre os partidários da PA nos contextos organizacional e tecnológico, a orientação é mais "acomodada", procurando transformações satisfatórias e compatíveis com a adaptação e o funcionamento das organizações existentes (THIOLLENT, 2011, p. 105 , grifo do autor).

Marcela Gajardo compartilha das ideias de Thiollent. Para a referida autora, ao invés de caracterizar a ciência "como uma atividade que não assume [e] nem explicita suas opções frente ao tipo de sociedade em que surge e se desenvolve e frente a grupos e setores a que beneficia", passamos a "postular a necessidade de vincular a atividade científica aos processos gerais de transformação sócio-política" (GAJARDO, 1986, p. 15), daí a vocação política, característica da linha crítico-emancipatória de pesquisa-ação, voltada para os interesses sociais e seus objetivos vinculados à transformação da realidade desigual e excludente que atinge grande parte dos países subdesenvolvidos.

Quanto à diversidade de formatos de PA, verificamos quadro de falta de consenso entre os autores. Barbier (2007), por exemplo, entre outros tipos, menciona a pesquisa-ação integral formulada por André Morin (2004), além de propor e defender sua própria linha de PA: a pesquisa-ação existencial. Franco (2005) observa, em recentes trabalhos, pelo menos três distintas propostas: i) pesquisa-ação colaborativa; ii) pesquisa-ação crítica; iii) pesquisaação estratégica. Em alguns casos, a exemplo da classificação proposta por Franco (2005), o elemento de distinção entre essas várias correntes está centrado na posição ocupada pelo pesquisador durante o processo. Em outros, como é o caso da linha que estamos assumindo aqui, parece que o critério de distinção está essencialmente ligado às intencionalidades da proposta desenvolvida.

Voltando às principais características da PA, como já foi explicitado, é modalidade que pressupõe horizontalidade entre os sujeitos envolvidos. É uma forma de pesquisa visceralmente participativa, a ponto de alguns autores, como Barbier (2007), por exemplo, defenderem a ideia de pesquisador-coletivo: sujeitos e pesquisadores interagem na produção de diagnósticos, ações, reflexões, etc. Isso implica diretamente a participação das pessoas envolvidas no processo. Como diria Barbier (2007) "não há pesquisa-ação sem participação coletiva" (p. 70). Os problemas de pesquisa e suas conexões com os problemas a serem atacados não podem ser impostos pelos pesquisadores.

Com efeito, a definição dos problemas e objetivos da ação deve ser empreitada de natureza coletiva, mediada e assessorada pelos pesquisadores, mas definida em quadro de 
partilha entre todos os envolvidos (MORIN, 2004; BARBIER, 2007; THIOLLENT, 2011). Por isso, os autores supracitados sublinham a ideia de contrato como um elemento essencial da PA. O contrato é uma espécie de acordo negociado entre as partes (pesquisadores e atores), estabelecendo aspectos diversos que envolvem os processos gerados no contexto da PA, perpassando desde os detalhes inerentes à imersão e aceitação dos pesquisadores pelo grupo/instituição, a definição dos objetivos, papéis e tarefas a serem desempenhadas, a lógica que comandará as tomadas de decisão ao longo do projeto, até as formas de avaliação e publicização dos resultados alcançados.

A ação a ser desencadeada corresponde aquilo que é necessário ser feito (ou transformado) para a solução do problema e "ocorre somente se for do interesse dos grupos e concretamente elaborada e praticada por eles" (THIOLLENT, 2011, p. 126).

Em termos de etapas envolvidas no projeto, as diversas fases da PA podem ser amparadas no conhecido esquema de ciclo em espiral, incluindo processos "de planejamento, de ação, de observação, de reflexão, depois um novo planejamento da experiência em curso" (BARBIER, 2007, p. 60).

Temos também as etapas propostas por Thiollent (2011) que podem assumir natureza diversificada: educativa, formativa, diagnosticadora, técnica, comunicativa, conscientizadora, política, cultural, etc.

Essas etapas poderiam ser sumariamente explicitadas numa organização da investigação que passa pela própria concepção e definição das prioridades da pesquisa, do desenrolar das atividades propostas e da avaliação das ações planejadas (Figura 1).

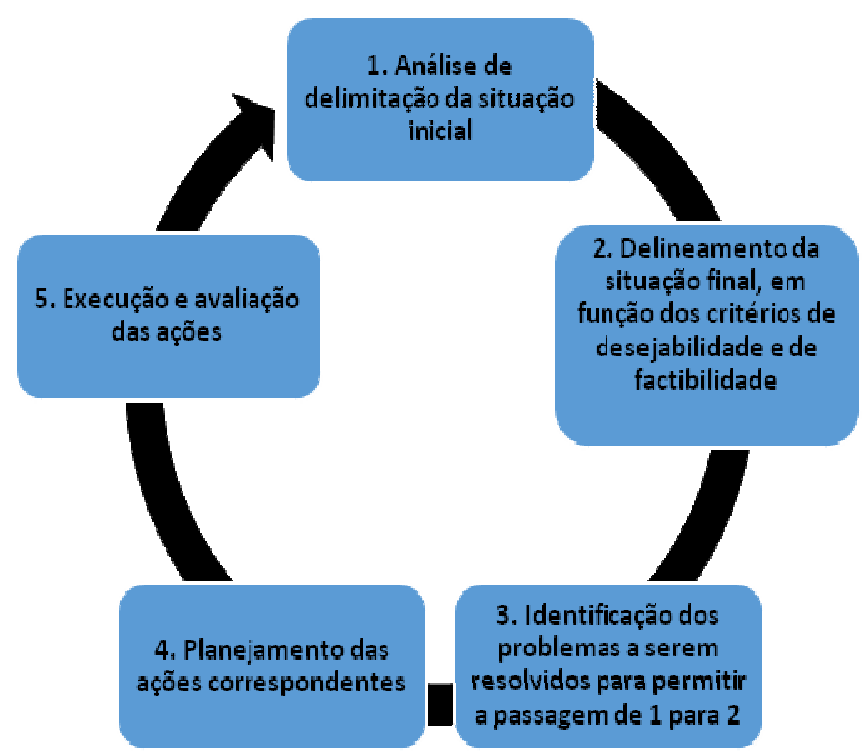

Figura 1 - Formulação de projetos de pesquisa-ação segundo Thiollent (2011). A figura é uma adaptação das ideias do referido autor.

Fonte: autores.

Segundo El Andaloussi (2004, p. 86) a PA passa por etapas nas quais temos que “diagnosticar uma situação, iniciar uma ação, acompanhá-la, observá-la, conferir-lhe sentido, avaliando-a e incitando-a a desencadear novas ações”. Na mesma linha Dionne (2007), 
didaticamente, menciona quatro fases principais para os processos envolvidos em uma PA: “i) identificação das situações iniciais; ii) projetação da pesquisa e da ação; iii) realização das atividades previstas; iv) avaliação dos resultados obtidos"1 (DIONNE, 2007, p. 22). A vantagem no uso de algumas das variações desses modelos em espiral é que eles permitem ajustes nos rumos definidos para o processo de ação e busca da solução de problemas. Neste sentido, a PA é "biodegradável": não pode ser projeto inteiramente planejado, definido ou predeterminado a priori. O processo "deve ser, então, o mais aberto e flexível possível para que se possa adequar à trajetória seguida pelo pesquisador e pelos atores" (EL ANDALOUSSI, 2004, p. 109).

Em relação a detalhes relativos à produção de dados, dada a complexidade dos processos envolvidos na PA, o interessante é utilizar múltiplas estratégias e recursos, incluindo o expediente da observação participante, técnicas de dinâmica grupal, recolha de documentos, grupos focais, filmagens, entrevistas, etc. É importante produzir dados em diferentes ângulos e perspectivas, procurando construir uma visão aprofundada do processo desenrolado durante o projeto, envolvendo a dimensão qualitativa e interpretativa.

Embora não assumam, como em outras modalidades de pesquisa, o papel central na definição dos rumos do processo investigativo, já que a definição das prioridades da pesquisa depende de processos dialógicos entre pesquisadores e sujeitos implicados (pesquisadorcoletivo), os pesquisadores "desempenham um papel ativo no equacionamento dos problemas encontrados, no acompanhamento e na avaliação das ações desencadeadas em função dos problemas" que a investigação deseja atacar (p. 21). Neste sentido, no contexto de desenvolvimento do processo, esses profissionais são chamados de mediadores, motivadores, orientadores, assessores, facilitadores, etc. (GERALDI et al., 2003; DEMO, 2004; BARBIER, 2007).

Ainda em relação ao papel exercido pelos pesquisadores, devemos lembrar que existem inúmeros casos, ilustrados na literatura, sobre o desenvolvimento de PA fora do contexto acadêmico ${ }^{2}$. Em tais situações a figura do pesquisador acadêmico assume, inclusive, papel secundário. Em outras ocasiões, o processo é disparado pelo grupo/comunidade interessado, que pode acionar o pesquisador em algum momento e até dispensar sua participação em outro.

Mas, o que nos interessa no âmbito deste trabalho, são os projetos de PA desenvolvidos por conta da realização de estudos acadêmicos. Assim, fixando atenção sobretudo naqueles relacionados às dissertações e teses, os desafios se amplificam, dadas as

\footnotetext{
${ }^{1}$ Uma boa descrição dessas etapas, com informações sobre a diversidade de encaminhamentos em cada uma delas pode ser encontrada em Dionne (2007, parte II).

${ }^{2}$ Veja, por exemplo, Brandão (1999) e Bogdan e Biklen (2010).
} 
limitações de tempo (sobretudo no mestrado) e demais exigências do design singular exigido para os projetos de pesquisa-ação. Talvez isso explique a escassez de estudos de PA na área de Educação em Ciências, hipótese que estamos assumindo aqui e que precisa ser confirmada por meio dos estudos posteriores.

Para aqueles que desejam se enveredar nos caminhos da Pesquisa-Ação, na sequência, o Quadro 1, formulado conforme aportes encontrados na literatura, oferece um conjunto não exaustivo de indagações orientadoras. Elas ajudam a pensar nas características básicas para a delimitação de projetos de pesquisa-ação em instituições escolares e universitárias, ou ainda em contextos não formais de educação. Também serão utilizadas na análise aqui desenvolvida em relação a um conjunto de DTs em Ensino de Biologia devidamente selecionadas para a pesquisa relatada na sequência do presente artigo.

Quadro 1 - Conjunto de indagações úteis para caracterização de uma pesquisa-ação.

i) Quanto aos objetivos:

1.1 - Há ação deliberada visando a modificação e/ou a transformação de uma realidade?

1.2 - O pesquisador não impõe ou pelo menos não direciona individualmente o problema da pesquisa?

1.3 - A definição de problemas, objetivos, prioridades e ações do projeto é realizada em regime de partilha entre os participantes (pesquisadores e atores), respeitando e atendendo aos interesses do grupo envolvido?

1.4 - Pesquisadores e atores interagem coletivamente para modificar situações e gerarem conhecimentos sistematizados em relação ao processo desenvolvido?

1.5 - As ações desenvolvidas partem de problemas oriundos e/ou vivenciados pelos participantes?

ii) Sobre as relações entre os atores envolvidos:

2.1 - A relação estabelecida entre as partes envolvidas é horizontal/democrática/dialógica?

2.2 - Existe participação coletiva ao longo do projeto? É um projeto que fomenta a participação de todos?

2.3 - Se configura, ao longo do projeto, a figura do pesquisador coletivo?

iii) Sobre a metodologia de trabalho:

3.1 - O planejamento é flexível e ajustável?

3.2 - São utilizadas práticas dialógicas e participativas para definição dos rumos do projeto?

3.3 - Utiliza alguma variação das espirais cíclicas inspiradas no trabalho de Lewin como forma de conduzir o projeto, isto é, o desenvolvimento do projeto passa por etapas/fases incluindo: i) identificação da situação inicial (diagnóstico); ii) planejamento da pesquisa e das ações; iii) realização das atividades previstas; iv) avaliação/reflexão sobre as ações e os resultados obtidos?

3.4 - São utilizadas múltiplas estratégias e recursos no processo de produção de dados sobre o projeto?

3.5 - A análise de dados e resultados da pesquisa é desenvolvida coletivamente?

iv) Sobre os resultados alcançados:

4.1 - Há geração de produto acadêmico (tese, dissertação, artigo, etc.)?

4.2 - Os resultados foram publicizados e discutidos em nível grupal, evitando que os alcances do projeto se plasmem apenas em mero texto acadêmico?

v) Sobre as intencionalidades inerentes ao projeto desenvolvido:

5.1 - Assumem intencionalidades pragmáticas?

5.2 - Assumem intencionalidades crítico-emancipatórias?

Fonte: Elaborado pelos autores

\section{Metodologia}

O período de abrangência da pesquisa começa em 1972, ano em que os primeiros trabalhos em Ensino de Biologia foram defendidos no país (TEIXEIRA, 2008; MEGID 
NETO, 2014). O marco final é 2011, ano estabelecido para finalizar a coleta de dados junto aos bancos de informações sobre DTs. Em nosso caso, além da busca no "Banco de Teses BT/CAPES"3, principal fonte para a pesquisa que toma como objeto de estudo as DTs, também consultamos as páginas da internet dos programas de pós-graduação cadastrados nas áreas de Educação e Ensino da CAPES; visitamos também as bibliotecas on-line de Instituições de Ensino Superior (IES) onde esses programas estão instalados. Adicionalmente, para completar a coleta de dados, visitamos a Plataforma Lattes - CNPq, examinando os currículos de potenciais orientadores vinculados ao Ensino de Biologia para identificar suas orientações concluídas. Para isso, utilizamos, como base para consulta uma lista contendo 232 nomes de pessoas que formaram a Comissão Científica para trabalhos submetidos ao $V$ Encontro Nacional de Ensino de Biologia, realizado na USP em setembro de $2014^{4}$.

Com efeito, este processo de triangulação de fontes para coleta de informações garantiu que parte significativa das DTs em Ensino de Biologia defendidas no país no período sob investigação fossem "capturadas", embora não seja possível afirmar que todas as DTs defendidas nesses 40 anos estejam retratadas no conjunto de documentos constituído para dar base para a nossa pesquisa. Ao final deste processo de busca, encerrado em 2015, os resultados obtidos permitiram a totalização de 1000 referências. Depois, selecionamos para constituir o corpus de análise somente os trabalhos em que os autores, explicitamente, mencionaram nos títulos, resumos e/ou palavras-chaves, a realização de uma pesquisa-ação. Ao aplicar este procedimento foram obtidos 24 DTs.

Esse conjunto de trabalhos foi examinado, em primeira etapa, conforme os seguintes descritores: a) ano de defesa e evolução quantitativa da produção acadêmica; b) IES onde os trabalhos foram desenvolvidos e distribuição geográfica; c) titulação; d) nível escolar privilegiado nos estudos acadêmicos; e) focos temáticos. Posteriormente, na parte principal da pesquisa, por meio da utilização de procedimentos ligados à análise de conteúdo - leitura, codificação, categorização e classificação - (FRANCO, 2008), examinamos mais detidamente os resumos, capítulos introdutórios e aqueles que descreviam metodologicamente o trabalho realizado. Os demais capítulos de cada dissertação ou tese foram examinados exploratoriamente conforme a necessidade de elucidar problemas e dúvidas em relação ao processo desenvolvido na pesquisa descrita.

A apresentação dos resultados é dividida em duas seções. A primeira é centrada numa breve apresentação das características gerais deste subconjunto de DTs. A segunda focaliza a caracterização das pesquisas realizadas conforme os princípios explicitados na literatura

\footnotetext{
3 Banco de Teses da CAPES: Coordenação de Aperfeiçoamento de Pessoal de Nível Superior: http://www.capes.gov.br/servicos/banco-de-teses.

4 Informações sobre essa Comissão Avaliadora podem ser encontradas no endereço eletrônico: http://www.sbenbio.org.br/ (Associação Brasileira de Ensino de Biologia).
} 
arregimentada para compor as referências teóricas apresentadas na seção anterior deste artigo. Operacionalmente, foram úteis nesta segunda parte do processo de análise, o conjunto de questões apresentadas no Quadro 1. Elas compõem parte de uma ficha de análise onde fixamos as principais informações obtidas durante a análise de conteúdo de cada trabalho, incluindo também aspectos como: contexto de aplicação do projeto, instituições e sujeitos envolvidos, duração do projeto, e, autores sobre pesquisa-ação utilizados para subsidiar o trabalho e a natureza das ações desenvolvidas.

\section{Análise de Resultados}

Características Gerais

Para iniciar a análise dos dados apresentamos no Quadro 2 informações gerais relativas a cada uma das DTs examinadas durante a investigação.Como foi dito, detectamos 24 DTs em que os autores mencionaram a realização de uma pesquisa-ação nos títulos, resumos e/ou palavras-chaves. Em temos percentuais, isso significa que este grupo de trabalhos acadêmicos corresponde a apenas 2,4\% da totalidade de DTs em Ensino de Biologia. O primeiro documento encontrado data de 1981, sendo defendido na Faculdade de Educação da UFBA. 
Quadro 2 - Informações gerais relativas Dissertações e Teses arroladas para a investigação.

\begin{tabular}{|c|c|c|c|c|c|c|}
\hline DOC & AUTOR & IES & ÁREA DO PROGRAMA & ANO & TITULAÇÃO & NÍVEL \\
\hline 055 & SILVA, TCPC & UFBA & Educação & 1981 & $\mathrm{M}$ & ES \\
\hline 937 & CUNHA, AMO & USP & Educação & 1999 & D & EF/EM \\
\hline 231 & MELLO, JT & UFPel & Educação & 2000 & $\mathrm{M}$ & EM \\
\hline 313 & BIZERRIL, MXA & UnB & Ecologia & 2001 & $\mathrm{D}$ & $\mathrm{EF} 2$ \\
\hline 109 & CARVALHO, W & PUC-SP & Educação & 2001 & $\mathrm{D}$ & EM \\
\hline 997 & MENDES, EB & UFSC & Engenharia de Produção & 2002 & D & EM \\
\hline 262 & OLIVEIRA, SS & UFPA & Educação em Ciências & 2004 & $\mathrm{M}$ & EM \\
\hline 400 & JORDÂO, RS & USP & Educação & 2005 & $\mathrm{D}$ & ES/EM \\
\hline 438 & CHUDO, ML & UNIFESP & Educação em Ciências & 2006 & $\mathrm{M}$ & ES \\
\hline 528 & PAULA, SR & USP & Ciências-Genética & 2007 & M & $\mathrm{EF} 2$ \\
\hline 579 & CARDINALI, SMM & PUC-MG & Educação em Ciências & 2008 & MP & EM \\
\hline 982 & MICO, FAC & UNICSUL & Educação em Ciências & 2008 & MP & EF2 \\
\hline 558 & SOUZA, JB & UMC & Biotecnologia & 2008 & $\bar{M}$ & EM \\
\hline 648 & EVANGELISTA, LM & UFG & Educação em Ciências & 2009 & M & ES \\
\hline 674 & ZANESCO, R & UNICSUL & Educação em Ciências & 2009 & MP & EM/EJA \\
\hline 768 & ALMEIDA, MP & UTFPR & Educação em Ciências & 2010 & MP & ES \\
\hline 762 & BASTOS, MER & UFC & Educação em Ciências & 2010 & MP & EM \\
\hline 716 & COSWOSK, ED & PUC-MG & Educação em Ciências & 2010 & MP & ES \\
\hline 748 & LIMA, LF & UFRPE & Educação em Ciências & 2010 & $\mathrm{M}$ & ES \\
\hline 693 & LOTÉRIO, J & FURB & Educação em Ciências & 2010 & MP & $\mathrm{EF} 2$ \\
\hline 160 & MOURÃO, IC & UEA & Educação em Ciências & 2010 & MP & ES \\
\hline 777 & YOSHIKAWA, RCS & USP & Educação em Ciências & 2010 & $\mathrm{M}$ & EM/EJA \\
\hline 809 & ARAÚJO JR, AC & UnB & Educação em Ciências & 2011 & MP & EF/EJA \\
\hline 854 & MORAES, MJ & USP & Educação em Ciências & 2011 & $\mathrm{M}$ & EM \\
\hline
\end{tabular}

Legenda: Código do Documento: (DOC); Titulação: Mestrado (M); Mestrado Profissional (MP); Doutorado (D). Nível de Ensino: Ensino Fundamental (EF); Ensino Médio (EM); Educação Superior (ES).

A distribuição diacrônica desse conjunto de trabalhos é observada na figura apresentada na sequência (Figura 2).

140

120

100

80

60

40

20

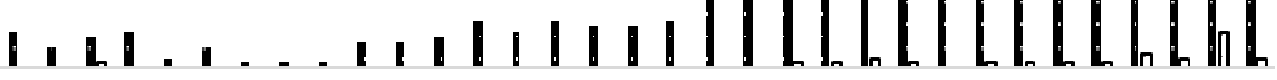

72737475767778798081828384858687888990919293949596979899000102030405060708091011

- DTs em Ensino de Biologia (EB) CDTs EB Pesquisa Ação

Figura 2 - Gráfico da distribuição diacrônica das 1000 DTs em Ensino de Biologia defendidas no período 1972 - 2011 (colunas em cor preta) em comparação com a evolução do subgrupo desses trabalhos que foram caracterizados pelos autores como pesquisa-ação (colunas em cor branca).

Observando o gráfico com foco nas colunas em cor branca, notamos que este grupo de trabalhos representa pequena parcela da totalidade de DTs. Se considerássemos todas as 
pesquisas de natureza interventiva detectadas no conjunto das 1000 DTs em Ensino de Biologia, teríamos 250 documentos, isto é, $25 \%$ da totalidade, entre as quais, apenas 24 foram designadas pelos próprios autores como dentro da modalidade de pesquisa-ação. Assim, considerando tais informações, essas "pesquisas-ações" representariam algo em torno de 10\% entre as investigações caracterizadas pela sua natureza articuladora entre ação e investigação. As demais se aplicam a casos que classificamos como pesquisas experimentais, pesquisa de aplicação de sequências e recursos didáticos, pesquisa sobre a própria prática, pesquisa \& desenvolvimento, etc.

Na série histórica apresentada no gráfico, observa-se que a presença dos trabalhos caracterizados pelos autores como pesquisa-ação é residual o tempo todo, mas fica um pouco mais intensa nos anos 2000, particularmente após 2008. O ano de 2010 é aquele que totaliza o maior número de trabalhos, com 7 DTs.

Quanto ao descritor titulação, temos 10 dissertações de mestrado acadêmico, 9 dissertações de mestrado profissional e 5 teses de doutorado. Esses trabalhos foram produzidos, basicamente, em programas de Educação em Ciências (15 documentos) e Educação (5 documentos), mas também apareceram trabalhos em programas das áreas de Ciências Biológicas, Engenharia de Produção e Biotecnologia. A distribuição dessas DTs por instituições de ensino superior (IES) mostra a predominância de estudos realizados no setor público: 11 em IES federais; 6 em estaduais; 1 em instituição municipal. As instituições privadas comparecem com 6 trabalhos. A análise dos dados obtidos não permite a construção de inferências seguras sobre grupos caracterizados por realizar sistematicamente essa modalidade específica de investigação. Entretanto, é interessante registrar que a USP aparece como a instituição que aglutinou o maior número de trabalhos (5 DTs).

Ao cruzarmos as informações obtidas pelos descritores "focos temáticos" e "nível de ensino", começamos a desvelar detalhes sobre o contexto de realização desses trabalhos acadêmicos. Vejamos algumas informações fixadas na Tabela 1, que junto com a análise de conteúdo dos referidos trabalhos, permitiu a construção dos comentários que apresentaremos na sequência. 
Tabela 1 - Distribuição das DTs do grupo investigado pelos descritores focos temáticos e níveis de ensino.

\begin{tabular}{|c|c|c|c|c|c|c|}
\hline \multirow[t]{2}{*}{ Linhas/Focos Temáticos } & \multicolumn{5}{|c|}{ Níveis de Ensino } & \multirow[t]{2}{*}{ Totalização } \\
\hline & $\mathbf{E F}$ & EF/EM & EM & EM/ES & $\mathbf{E S}$ & \\
\hline Ensino-Aprendizagem & 5 & & 3 & & 5 & 13 \\
\hline Formação de Professores & & 1 & 2 & 1 & 1 & 5 \\
\hline Recursos Didáticos & & & 4 & & & 4 \\
\hline Questões Curriculares & & & 1 & & & 1 \\
\hline Características dos Alunos & & & 1 & & & 1 \\
\hline Características dos Professores & & 1 & & & & 1 \\
\hline Educação Ambiental & 1 & & & & & 1 \\
\hline Totalização & 6 & 2 & 11 & 1 & 6 & 26 \\
\hline
\end{tabular}

Legenda: O número total ultrapassa 24, pois uma parte das DTs foi classificada em mais de um foco temático.

Como se nota, a atenção ao contexto do ensino fundamental aparece em 8 DTs; ao contexto do ensino médio em 14 DTs, e à Educação Superior, em 7 DTs. A análise da distribuição dos trabalhos pelos focos temáticos é interessante para examinarmos o contexto de aplicação inerente às ações desenvolvidas nesses trabalhos. Neste aspecto, constatamos número significativo de DTs dedicadas ao foco Ensino-Aprendizagem. São 13 DTs encontradas em todas as faixas de ensino, com contextos de aplicação basicamente vinculados à sala de aula, em situações envolvendo o planejamento e aplicação de uma disciplina (5 DTs); delineamento e aplicação sequências didáticas (4); de projetos de oficinas/educacionais e minicursos (4).

Em relação ao foco Formação de Professores temos 5 documentos, entre os quais, dois estão associados ao contexto da formação inicial: um focaliza proposta de experiência de estágio coletivo tutorado; e outro está baseado na elaboração e aplicação de um plano de ação para a disciplina "Didática das Ciências" para Licenciandos de Biologia e Química. Os outros três trabalhos estão centrados em situações de formação continuada: um relacionado à aplicação de processo de educação continuada para professores, centrado na proposta de Mudança Conceitual e preocupado com os reflexos dessa formação nas concepções epistemológicas e de ensino-aprendizagem dos referidos docentes participantes; outro relacionado à aplicação de um curso de formação continuada de inspiração construtivista (aprendizagem significativa; mapas conceituais); e, por fim, um envolvendo trabalho de parceria entre a pesquisadora e uma professora do ensino médio numa proposta baseada na ideia de alfabetização científica.

Já no foco temático Recursos Didáticos todas as 4 DTs estão vinculadas ao contexto do Ensino Médio: duas relacionadas à produção, testagem e desenvolvimento de modelos táteis aplicáveis às aulas de Biologia envolvendo estudantes portadores de deficiência visual; uma envolvendo a utilização de textos de divulgação científica; e um último trabalho dedicado a estudar a interação de estudantes com um Ambiente Virtual de Aprendizagem (Moodle).

Além do trabalhos já mencionados, temos outros quatro documentos dispersos em diferentes focos temáticos: i) um envolvendo questões curriculares, particularmente voltado 
para a Biologia ensinada na educação média, relatando uma parceria entre o pesquisador e 5 professores trabalhando em torno de uma proposta de currículo para o ensino de Biologia baseado na ideia de Biofilia; ii) outro que relata uma pesquisa focada em torno de um projeto voltado para a temática do Cerrado, preocupado em propor e difundir informações sobre o Bioma de forma a intensificar o trabalho com essa temática nas escolas do ensino fundamental (Educação Ambiental); iii) outro centrado na formação e na análise das concepções epistemológicas de professores, pensando em estratégias de mudança conceitual (Características dos Professores); iv) e, por fim, um trabalho ligado a projeto que promoveu oficinas sobre DST's, Aids, gravidez, etc. junto a grupos de estudantes do EM (Características dos Alunos), procurando discutir suas concepções e alterá-las em relação a diferentes problemas atinentes a sua sexualidade.

Ainda em relação ao contexto de aplicação desses trabalhos, predominam o desenvolvimento de projetos que acontecem em salas de aula (20/24 DTs), nos níveis de ensino supracitados. Em tais casos, estão os projetos envolvendo aplicações de sequências didáticas, oficinas, metodologias de ensino, disciplinas de graduação, atividades lúdicas, etc. Em alguns casos, tivemos também o envolvimento da comunidade (Doc. 982) e da escola em diferentes atividades desenvolvidas (Docs. 982; 997; 313; 109; 400). Em relação a duração dos projetos relatados nas pesquisas analisadas, os dados indicam que temos situações nas quais ocorrem processos desenvolvidos em curto espaço de tempo (algumas horas-aula; semanas). Todavia, na maior parte dos casos (21/24), a duração dos projetos passa pela escala de meses, semestres e até alguns anos. Veja quadro apresentado na sequência:

Quadro 3 - Duração das ações envolvidas nas pesquisas sob investigação.

\begin{tabular}{|l|l|l|}
\hline ESCALA DE DURAÇÃO & DOCUMENTOS & TOTAL \\
\hline Aulas, semanas & $762 ; 558,809$ & 3 \\
\hline Meses (de $1-5$ meses) & $262 ; 528 ; 579 ; 693 ; 748 ; 777$ & 6 \\
\hline Semestre(s) & $55 ; 160 ; 231 ; 438 ; 648 ; 674 ; 716 ; 768$ & 8 \\
\hline Ano(s) & $109 ; 313 ; 400 ; 854 ; 982 ; 937 ; 997$ & 7 \\
\hline & & 24 \\
\hline
\end{tabular}

Fonte: Elaborado pelos Autores.

Parece-nos que essa é uma característica das pesquisas que possuem natureza interventiva, qual seja, a necessidade de despender mais tempo para a execução das várias etapas da investigação, incluindo a fase de intervenção (ação) que, muitas vezes, pode envolver um semestre letivo, um ano escolar, ou mesmo, mais tempo se o projeto tiver continuidade ultrapassando, por exemplo, o limite de um ano letivo escolar/universitário.

Quanto aos sujeitos participantes nessas pesquisas e as relações estabelecidas entre eles e os pesquisadores, observamos as seguintes situações:

- Pesquisador e Estudantes: 579; 982, 674, 528, 438, 854, 231, 809, 777, 558, 693, 762 (12 DTs);

- Pesquisador e Estudantes (licenciandos): 400, 748, 160, 648, 768 (5 DTs); 
- Pesquisador e Professor ou Grupo de Professores: 109; 262; 937 (3 DTs);

- Pesquisador-Professores-Alunos: 55; 313; 997 (3 DTs);

- Pesquisador-Monitores-Estudantes (ES): 716 (1 DT).

Foi interessante analisar este quesito, dada a atenção que a literatura sobre pesquisaação atribui para o estabelecimento de relações interativas e dialógicas entre os sujeitos envolvidos no projeto. Mais do que isso, examinamos o grau de participação dos sujeitos envolvidos na tentativa de verificar a presença do pesquisador-coletivo a que nos referimos na seção de referências teóricas do artigo (BARBIER, 2007). Os resultados expressam as dificuldades que temos para romper a estrutura pesquisador $\rightarrow$ pesquisado (objeto de estudo). Considerando as 24 DTs aqui examinadas, identificamos apenas dois casos (Docs. 160; 262) em que ficou caracterizada uma quebra da relação hierárquica entre pesquisador e sujeitos (professores/estudantes), com participação efetiva dos envolvidos na definição dos rumos do projeto de pesquisa.

Assim temos uma situação que confirma a dificuldade dos sujeitos, sejam eles professores, estudantes, licenciandos etc., serem engajados no projeto, junto com o pesquisador, de forma a atuar intelectual e ativamente, participando "na escolha das questões a serem investigadas, na elaboração do projeto de pesquisa, e até mesmo a partilhar os resultados da pesquisa" (ZEICHNER, 1998, p. 212). Claro que o perfil dos trabalhos examinados dificulta a efetivação desse tipo de situação, dado que em pesquisas de mestrado e doutorado, ocorre a tendência de centralização e controle das decisões que definem os rumos da investigação nas mãos de uma única pessoa - o mestrando/doutorando, no máximo com influência em maior ou menor grau do orientador. Certamente, este é um ponto que dificulta a caracterização da maior parte desses trabalhos, como projetos de pesquisa-ação.

Cotejando os dados encontrados com a literatura sobre pesquisa-ação

Passamos a examinar, a partir deste ponto, outros aspectos na tentativa de identificar entre os trabalhos analisados, aqueles que se aproximaram de um design de pesquisa-ação conforme as características mencionadas na literatura especializada. Um primeiro ponto a destacar está sintetizado na Figura 3. Ela traz o conjunto de 17 características de pesquisaação arroladas junto a literatura e apresentadas no Quadro 1. No gráfico, elas aparecem listadas no eixo vertical, por meio de seus respectivos códigos $(1.1 ; 1.2 ; 1.3$; etc.). O eixo horizontal quantifica as DTs em Ensino de Biologia examinadas durante a investigação. Para cada característica, os documentos que, em nossa avaliação, não atendiam o critério indicado foram contabilizados do lado esquerdo (zona cinza); e os que atendiam o critério indicado, foram contabilizados do lado direito (zona escura). Salientamos que os critérios do grupo 5 $(5.1 ; 5.2)$ não são utilizados neste exercício de aplicação do Quadro 1 para discriminar os trabalhos enquadrados como PA, já que eles somente ajudam a compreender as 
intencionalidades pragmáticas e/ou emancipatórias explícitas ou implícitas nos trabalhos aqui descritos e examinados.

Figura 3 - Quantidade de Dissertações e Teses que atenderam ou não aos diferentes critérios para caracterização de pesquisa-ação.

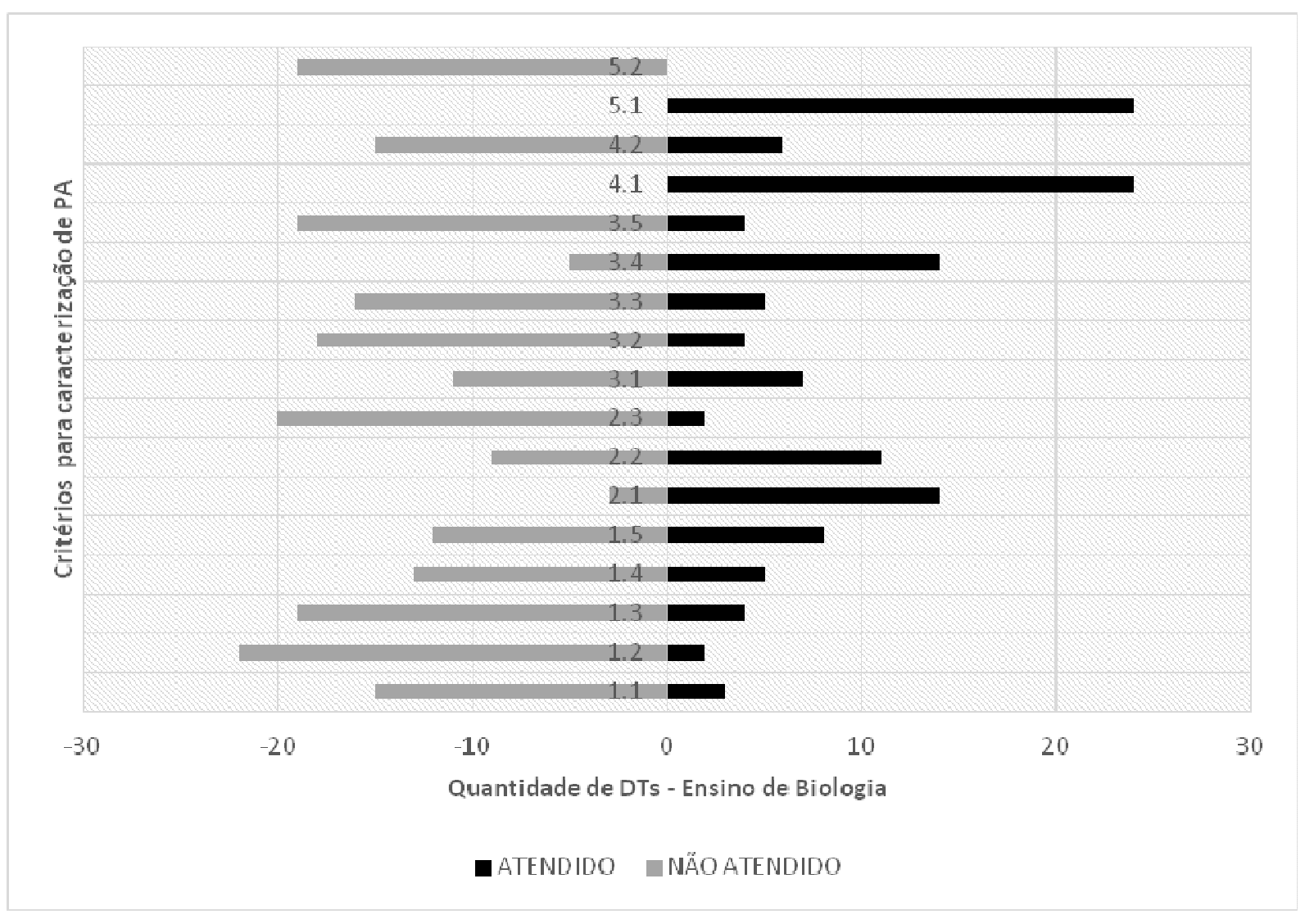

Fonte: Elaborado pelos Autores.

Entre os critérios considerados atendidos por parte substantiva dos documentos analisados, estão o item 4.1 (geração de produto acadêmico), já que todos os trabalhos se referem a pesquisas desenvolvidas no âmbito de cursos de mestrado/doutorado, gerando, portanto, teses e dissertações; e o item 5.1 (intencionalidade pragmática), posto que os trabalhos, em seu conjunto, buscam mudanças em concepções e práticas, mobilizam docentes para o desenvolvimento profissional, buscam a prática da reflexão no trabalho realizado pelos professores, desejam ganhos formativos e de aprendizagem para os estudantes, além de mudanças de comportamento e atitudes dos alunos, trabalham para minimizar dificuldades dos alunos em relação à aprendizagem de determinados conceitos e informações, planejam e testam estratégias e recursos didáticos, etc.

Outros dois critérios são atendidos por pouco mais da metade das dissertações e teses examinadas (14 documentos). São eles: 2.1: A relação desenvolvida entre as partes envolvidas durante as ações é horizontal/democrática/dialógica; 3.4: São utilizadas múltiplas estratégias e recursos no processo de produção e coleta dos dados de pesquisa sobre o projeto realizado. 
Do lado esquerdo do gráfico estão as DTs que não atenderam os critérios listados para caracterização de pesquisa-ação. O primeiro a se destacar, e de certa forma, pensamos que isso era algo esperado, é o item 1.2 (O pesquisador não impõe ou pelo menos não direciona individualmente o problema de pesquisa). Com efeito, em 22 das 24 DTs ocorreu justamente o contrário, com o pesquisador direcionando totalmente as definições inerentes ao problema de pesquisa, ou seja, o problema da pesquisa já estava definido na situação inicial de aplicação do projeto e o processo fica sob controle absoluto do pesquisador em sua integralidade, excluindo a possibilidade de que os outros sujeitos envolvidos (alunos, licenciandos, professores) participassem das diversas fases do projeto de pesquisa. A questão é: há como evitar isso em trabalhos de mestrado e doutorado? Em tese sim, mas, convenhamos, a situação mais frequente é caracterizada pela centralidade do pesquisador na definição dos rumos do projeto.

Outros cinco itens são também fortemente desconsiderados nos trabalhos analisados: 1.3) A definição de problemas, objetivos, prioridades e ações do projeto é realizada em regime de partilha entre os participantes (pesquisadores e demais atores), respeitando e atendendo aos interesses do grupo envolvido? (não atendido em 19/24 casos); 2.3) Se configura, ao longo do projeto, a figura do pesquisador coletivo? (não atendido em 20/24 casos); 3.2) São utilizadas práticas dialógicas e participativas para definição dos rumos do projeto de pesquisa? (não atendida em 18/24 casos); 3.5) A análise de dados e resultados da pesquisa é desenvolvida coletivamente? (não atendido em 19/24 casos); 3.3) Utiliza alguma variação das espirais cíclicas inspiradas no trabalho de Lewin como forma de conduzir metodologicamente o projeto de pesquisa? (não atendido em 16/24 casos).

Para fechar a análise dos dados contidos no gráfico, vale mencionar que dos 15 itens diretamente utilizados para caracterizar pesquisa-ação, apenas cinco são atendidos por mais de metade da DTs analisadas. Adicionalmente assinalamos que 10 dos 15 itens, segundo nossa avaliação, não foram atendidos por pelo menos metade dos trabalhos examinados. Por fim, cabe um comentário em relação ao item 5.2, que é útil para caracterizar se o trabalho examinado explicitou interesses crítico-emancipatórios. A análise apontou que 19 DTs não expressam qualquer intencionalidade neste sentido. Em outros casos, a análise integral dos textos não permitiu captar algo neste quesito. O fato é que a totalidade dos trabalhos menciona explicitamente interesses pragmáticos. Assim, em relação a essa tendência, podemos ter um quadro alinhado com o argumento apontado por Zeichner (1997) no sentido de que os pesquisadores caminham de questões que inicialmente julgam como sendo de natureza mais prática, como aqueles relativos à aplicação de sequências e recursos didáticos, ou a administração de uma sala de aula entre outras questões técnicas/práticas. A esperança do referido autor é que, com o tempo, se prosseguirmos com as práticas de pesquisa e reflexão, 
há possibilidade para o alcance de questões que são de cunho político e social mais amplo, inclusive buscando a igualdade e justiça social, desde que haja a preocupação explícita com essas dimensões. Talvez por isso, no conjunto de trabalhos examinados predomine a dimensão prática em relação à emancipatória.

Além dos critérios utilizados para amparar a análise dos trabalhos sob investigação, procuramos identificar também os autores ligados à pesquisa-ação citados nos respectivos trabalhos. Apesar de todos as 24 DTs mencionarem a realização de uma pesquisa-ação, identificamos que $1 / 3$ desses trabalhos sequer cita qualquer autor ligado à pesquisa-ação em seu texto. Nos 2/3 das DTs onde aparecem esses autores, o mais citado é Michel Thiollent, particularmente o livro "Metodologia da Pesquisa-Ação", que é mencionado em 13 das 24 DTs. Renê Barbier aparece citado em 7 DTs. Outros autores são citados pontualmente como é o caso de K. El Andaloussi, J. Mc Kernan, M. A. S. Franco, D. Tripp, J. Elliott, K. M. Zeichner, W. Carr e S. Kemis.

Outro ponto a salientar, considerando as informações encontradas na maior parte dos textos são citações avulsas de autores ligados à PA, empregadas, muitas vezes fora de contexto. Queremos dizer com isso que, na descrição metodológica desses trabalhos faltam informações pormenorizadas para explicar como o projeto se encaixa numa estrutura de pesquisa-ação. Por exemplo, um dos excertos mais encontrados foi o seguinte:

\begin{abstract}
a pesquisa-ação é um tipo de pesquisa social com base empírica que é concebida e realizada em estreita associação com uma ação ou com a resolução de um problema coletivo e no qual pesquisadores e participantes representativos da situação ou do problema estão envolvidos de modo cooperativo ou participativo (THIOLLENT, 2011, p. 20, grifo nosso).
\end{abstract}

Pois bem, em vários trabalhos ele aparece isoladamente no contexto da descrição metodológica explicitada pelo autor da DT, como se, de per si, garantisse o enquadramento do trabalho realizado como pesquisa-ação. Entretanto, para o referido enquadramento seria preciso observar os elementos da obra de Thiollent como um todo, na tentativa de compor uma perspectiva mais aprofundada sobre como o referido autor estrutura a sua ideia de pesquisa-ação e levá-la em consideração na execução integral do projeto de pesquisa. Entretanto, por vezes, isso simplesmente é ignorado. Com isso, acabamos por ter a utilização do termo de forma genérica, sem a avaliação do que ele significa em termos do delineamento para o trabalho de pesquisa. Uma discussão mais aprofundada sobre o uso de citações isoladas em trabalhos acadêmicos e científicos pode ser encontrada em Triviños (1987, p. 15).

Neste quadro de confusão e uso genérico e vago do termo PA, encontramos situação em que o autor caracterizava ao mesmo tempo sua pesquisa como pesquisa-ação e estudo de caso; outro tomou as diretrizes da pesquisa qualitativa propostas por Bogdan e Biklen (2010),

${ }^{5}$ Michel Thiollent. Metodologia da Pesquisa-Ação. Editora Cortez, 2011. 
adotando-as como se fossem específicas para a pesquisa-ação; houve ainda um exemplo de “pesquisa-ação" não centrada em ação, mas sim na análise de concepções dos estudantes; e o uso de pesquisa-ação como orientação para o desenvolvimento de uma disciplina. Neste caso, a pesquisa-ação não apareceu como modalidade de pesquisa, mas sim como fundamento para organizar a metodologia de ensino proposta para a disciplina, como o uso de seminários e a tomada de decisões sobre os rumos da disciplina. Parece-nos um caso de didatização de elementos da PA, convertendo-a numa metodologia de ensino. Ainda assim, tudo ficou muito centralizado nas mãos do pesquisador, de modo que, o que interessava é que a disciplina acontecesse segundo os rumos definidos inicialmente por ele.

Nossa conclusão, ao mencionar todos esses exemplos, é que parte significativa dos autores das DTs examinadas menciona pesquisa-ação de modo superficial, utilizando elementos fragmentados dessa modalidade de pesquisa. Ao finalizar a análise procuramos classificar cada um dos trabalhos dentro de diferentes modalidades de pesquisas de natureza interventiva, separando aqueles que, em nossa avaliação, conforme os critérios estabelecidos no Quadro 1, se distanciavam de propostas de pesquisa-ação. O produto desse processo classificatório mostrou os seguintes resultados:

- 1 trabalho caracterizado como pesquisa \& desenvolvimento, combinado com relato de experiência;

- 13 classificados como pesquisas de aplicação (sequências didáticas, disciplinas, oficinas, projetos, etc.);

- 3 classificados como pesquisas experimentais ${ }^{6}$

- 3 caracterizados como pesquisas dos autores sobre sua própria prática ${ }^{7}$, mas também demarcadas pela presença de traços de relatos de experiência;

- 4 classificados como pesquisa-ação pragmática.

Na sequência faremos uma breve descrição dos quatro exemplos que se enquadraram como casos de pesquisa-ação. O Doc. 109 descreve um projeto de aproximadamente dois anos, envolvendo o pesquisador e cinco professoras de Biologia, constituindo grupo que desenvolveu reuniões formativas e reflexivas, atividades realizadas junto a estudantes da educação básica e a produção de um conjunto de textos, depois convertido em um livro, compondo uma espécie de proposta curricular para o ensino de Biologia na educação média. É um trabalho de natureza pragmática, voltado para a formação continuada dos integrantes do

\footnotetext{
${ }^{6}$ Sobre as aproximações da pesquisa-ação com as pesquisas experimentais, Thiollent (2011) assinala que "a pesquisa-ação não deixa de ser uma forma de experimentação em situação real, na qual os pesquisadores intervêm conscientemente" (p. 28), mas também se afasta das perspectivas de investigação científica concebidas dentro de uma perspectiva positivista ou pós-positivista, como é o caso dos três exemplos identificados em nossa análise.

${ }^{7}$ Molina e Garrido (2010) caracterizam esses trabalhos como aqueles "em que o autor, na qualidade de professor, transforma seu trabalho em sala de aula em objeto de pesquisa: investiga as dificuldades de aprendizagem dos alunos; elabora e introduz um projeto inovador para tornar o ensino mais eficaz; documenta o processo como fonte de análise da experiência" (p. 33).
} 
grupo e, principalmente, para a produção de uma proposta de currículo baseada na ideia de biofilia.

O Doc. 160 é trabalho focado na formação inicial de professores, em particular, num projeto de elaboração e aplicação da disciplina "Didática das Ciências" em cursos de licenciatura em Biologia e Química durante um semestre. No início a pesquisadora acompanhou o trabalho de seu orientador junto aos alunos durante a referida disciplina; depois ela própria assume a condução do trabalho e, junto com os licenciandos, inicia um ciclo de espirais reflexivas de pesquisa-ação para conduzir os rumos da disciplina até a sua conclusão. As ações que acontecem fazem parte de atividades promovidas no contexto da referida disciplina: seminários, análise de propostas curriculares, visitas a escolas, etc. A nosso ver, temos aqui outro caso de pesquisa-ação pragmática, ou como afirma a própria autora, pesquisa-ação prático-colaborativa, limitada ao contexto de realização da disciplina e voltada para a minimização da dicotomia entre os conhecimentos específicos e o fazer pedagógico.

Por sua vez, o Doc. 262, envolve o relato de um trabalho de parceria entre a pesquisadora e uma professora do ensino médio. O projeto durou aproximadamente dois meses, adotando natureza formativa, com ênfase na formação continuada da professora participante. $\mathrm{O}$ trabalho realizado gira em torno de uma proposta pedagógica baseada na ideia de alfabetização científica, assumindo também contornos pragmáticos, possibilitando à professora um olhar mais reflexivo e investigativo sobre sua prática, no sentido de questionála e propor novos encaminhamentos (mudanças pedagógicas), portanto, é um projeto que buscou a melhoria da prática da professora participante, principalmente no sentido de que ela abandonasse posturas tradicionais de ensino, avançando para reflexões e práticas ligadas ao ensino como investigação.

Por fim temos o Doc. 400, também ligado à problemática da formação inicial de professores. A autora investiga as contribuições de um estágio coletivo, tutorado e realizado, segundo ela, numa perspectiva de pesquisa-ação, voltado para a elaboração de saberes profissionais dos licenciandos de um curso de Ciências Biológicas. O projeto durou aproximadamente um ano, com a autora, simultaneamente professora da escola onde o projeto foi realizado, atuando como tutora de estágio supervisionado para um grupo de licenciandos, se orientando pela prática reflexiva e pela busca da melhoria das ações pedagógicas cotidianas (interesses práticos) dos futuros professores.

\section{Considerações finais}

Conforme mostramos, a maior parte dos trabalhos analisados durante a investigação (20 entre as 24 DTs) não se enquadrou nos critérios propostos como basilares para o desenvolvimento de uma pesquisa alinhada com o design da pesquisa-ação. Neste sentido, 
nosso estudo se articula com a observação proposta por Thiollent (2011), segundo a qual, encontramos dissertações e teses, além de outras modalidades de publicações, em diversas áreas, "que adotam princípios de pesquisa-ação, às vezes de modo parcial” (p. 121).

Nos casos analisados nesta pesquisa, os aspectos que geraram dificuldades para esse enquadramento passam pelo centralismo da pesquisa nas mãos do pesquisador, pela inexistência de estrutura grupal e/ou coletiva, redundando na ausência da figura do pesquisador coletivo, isto é, os participantes continuam sendo tomados somente como objetos de pesquisa, não atuando como co-pesquisadores. Além disso, em boa parte dos casos, ao examinarmos o delineamento metodológico dos trabalhos selecionados, não detectamos as fases inspiradas na espiral cíclica ou pelo menos em alguma variante deste processo, envolvendo etapas de identificação de situação inicial (diagnóstico, levantamento de problemas), projetação da pesquisa e das ações, ações, avaliações e reflexões (CARR; KEMMIS, 1986; DIONNE, 2007; EL ANDALOUSSI, 2004). Por fim, os participantes não são chamados a analisar os dados em conjunto com o pesquisador e, os resultados obtidos, exceto em dois ou três casos, se limitaram ao produto de natureza tipicamente acadêmica (dissertação ou tese), ignorando-se a publicização e democratização dos resultados aos demais participantes e sujeitos envolvidos e de interesse no projeto. Neste ponto específico, vale lembrar da observação proposta por M. Thiollent em relação à PA: "A avaliação dos resultados [deve] ser efetuada pelos participantes e pelos pesquisadores. Os resultados são difundidos sem restrição. Uma das partes não pode pretender se apoderar deles exclusivamente" (THIOLLENT, 2011, p. 53).

O fato de lidarmos com dissertações e teses, dadas as características envolvidas no desenvolvimento desses estudos acadêmicos, parece dificultar a realização de pesquisa-ação nos moldes descritos pela literatura específica sobre o assunto, sobretudo porque a definição da temática e do próprio problema de pesquisa, em geral, parte dos interesses do mestrando ou doutorando. Outra limitação pode ser o tempo de titulação, sobretudo no mestrado atual, que gera obstáculos para a realização de projetos que demandam mais tempo para garantir a passagem pelas várias etapas de uma pesquisa-ação. Além disso, pesquisas de mestrado e doutorado, via de regra, caracterizam-se como empreendimentos individuais. É raro encontrar projetos que envolvam algum tipo de estrutura coletiva. Em função dessa situação os projetos acabam centralizados excessivamente nas mãos dos próprios autores.

Sobre o grupo de 24 trabalhos examinados, é preciso salientar que não estamos apontando qualquer crítica em relação à qualidade dos projetos realizados, nem tão pouco, colocando em dúvida as potenciais contribuições desses trabalhos para a área de Educação em Ciências, sobretudo por que eles estão incluídos numa parte ainda pequena de estudos de natureza interventiva, representando esforço significativo no sentido de articular teoria e 
prática dentro de nosso campo de investigação. Todavia, como foi observado, os resultados indicam que os autores estão se apropriando do slogan pesquisa-ação de forma equivocada, como se qualquer tipo de ação - pesquisa desenvolvida pudesse se caracterizar automaticamente como pesquisa-ação. Considerando que partimos de um universo de 1000 DTs em Ensino de Biologia, a análise mostrou o baixo número de pesquisas dessa natureza na produção acadêmica investigada e confirmou observações encontradas na literatura especializada, mostrando a confusão generalizada que envolve o emprego do rótulo "pesquisa-ação".

Talvez o uso vago e genérico do termo PA detectado em 20 das 24 DTs analisadas nesta pesquisa seja decorrência, junto com outros fatores, da frágil formação metodológica obtida pelos estudantes de nossos cursos de pós-graduação, característica já observada em estudos anteriores (SÁNCHES GAMBOA, 2007; CHISTÉ, 2016). A confusão metodológica é explícita em vários trabalhos, passando, por exemplo, pelos casos que confundem metodologia de pesquisa com metodologia de ensino, pela superficialidade com que os procedimentos metodológicos são descritos, pela confusão entre ação e pesquisa, e até pelos trabalhos acadêmicos que sequer contém capítulos ou seções para descrever a metodologia de pesquisa adotada.

É por isso que gostaríamos de reiterar algo já mencionado na introdução do artigo. A necessidade de evitar o uso de conceitos flexíveis em demasia. Se adotamos para a pesquisa que estamos desenvolvendo um determinado slogan, como é o caso da pesquisa-ação, ou outro qualquer (estudo de caso, pesquisa etnográfica, etc.) é preciso garantir condições mínimas de coerência entre a modalidade selecionada e o conteúdo da literatura disponível sobre o assunto. Uma das atitudes sempre desejáveis neste sentido seria consultar obras (livros, artigos, textos, etc.) dos principais autores dedicados a estudar e apresentar reflexões críticas e aprofundadas sobre o assunto. Adicionalmente, em linhas gerais, temos que lembrar que "a responsabilidade de toda a pesquisa é fazer o conhecimento avançar. Para que isso seja possível, é necessário dominar o conteúdo, os conceitos, os métodos e os procedimentos de cada área que se investiga" (GHEDIN; FRANCO, 2011, p. 7).

Para finalizar, é preciso frisar que todos os trabalhos classificados como pesquisa-ação pertencem ao foco temático Formação de Professores: duas teses de doutorado, uma dissertação de mestrado acadêmico e outra de mestrado profissional. O forte vínculo com a prática ou com questões práticas é uma marca desses trabalhos. Se por um lado, podemos detectar nessas DTs um tom excessivamente pragmático, por outro, podemos observar também, pelo menos nos quatro casos detectados e comentados a pouco, que os projetos realizados, apesar da manutenção de certo centralismo das ações desenvolvidas nas mãos dos pesquisadores, possibilitaram a criação de espaços mais interativos para 
professores/licenciandos e pesquisadores refletirem sobre suas práticas e buscarem alternativas para melhorá-las (ZEICHNER, 1997).

\section{Referências}

ANDRÉ, M. E. D. A. Pesquisa em educação: desafios contemporâneos. Pesquisa em Educação Ambiental, v. 1, n. 1, p. 43-57, 2006.

BARBIER, R. A pesquisa-ação. Brasília/DF: Líber, 2007.

BOGDAN, R.; BIKLEN, S. Investigação qualitativa em educação: uma introdução à teoria e aos métodos. Porto: Porto Editora, 2010.

BRANDÃO, C. R. A pesquisa participante e a participação da pesquisa: um olhar entre tempos e espaços a partir da América Latina. In: BRANDÃO, C. R.; STRECK, D. R. Pesquisa participante: o saber da partilha. Aparecida/SP: Ideias \& Letras, 2006. p. 21-54.

BRANDÃO, C. R. (Org.). Pesquisa participante. São Paulo: Brasiliense, 1999.

CARR; W. W.; KEMMIS; S. Becoming critical: education, knowledge and action research. London: Deakin University Press, 1986.

CHISTÉ, P. S. Pesquisa-Ação em mestrados profissionais: análise de pesquisas de um programa de pós-graduação em ensino de ciências e de matemática. Ciência \& Educação, v. 22, n. 3, p. 789-808, 2016

CHIZZOTTI, A. Pesquisa qualitativa em Ciências Humanas e Sociais. Petrópolis: Vozes, 2006.

DEMO, P. Pesquisa participante: saber pensar e intervir juntos. Brasília/DF: Líber, 2004.

DIONNE, H. A pesquisa-ação para o desenvolvimento local. Brasília/DF: Líber, 2007.

EL ANDALOUSSI, K. Pesquisas-Ações: ciências, desenvolvimento, democracia. São Carlos: EdUFSCar, 2004.

FRANCO, M. A. S. Pedagogia da Pesquisa-Ação. Educação e Pesquisa, v. 31, n. 3, p. 483$502,2005$.

FRANCO, M. L. P. B. Análise de conteúdo. Brasília/DF: Líber Livros, 2008.

GAJARDO, M. Pesquisa participante na América Latina. São Paulo: Brasiliense, 1986.

GATTI, B. A produção da pesquisa em Educação no Brasil e suas implicações socio-políticoeducacionais: uma perspectiva da contemporaneidade. In: III CONFERÊNCIA DE PESQUISA SÓCIO-CULTURAL, 3., Campinas/SP. Anais... Campinas/SP: FE; IEL, 2000.

GERALDI, C. M. G.; MESSIAS, M. G. M.; GUERRA, M. D. S. Refletindo com Zeichner: um encontro orientado por preocupações políticas, teóricas e epistemológicas. In: GERALDI, 
C. M. G.; FIORENTINI, D.; PEREIRA, E. M. A. (Orgs.). Cartografias do trabalho docente: professor(a) pesquisador(a). Campinas/SP: Mercado de Letras; ALB, 1998. p. 237-276.

GHEDIN, E.; FRANCO, M. A. S. Introdução. In: PIMENTA, S. G.; GHEDIN, E.; FRANCO, M. A. S. Pesquisa em educação: alternativas investigativas com objetos complexos. São Paulo: Loyola, 2011. p. 7-24.

GHEDIN, E.; FRANCO, M. A. S. Questões de método na construção da pesquisa em educação. São Paulo: Cortez, 2008.

GREENWOOD, D. J.; LEVIN, M. Reconstruindo as relações entre as universidades e a sociedade por meio da pesquisa-ação. In: DENZIN, N. K.; LINCOLN, Y. S. O planejamento da pesquisa qualitativa: teorias e abordagens. Porto Alegre: ArtMed, 2006. p. 91-113.

MEGID NETO, J. Origens e desenvolvimento do campo de pesquisa em Educação em Ciências no Brasil. In: NARDI, R.; GONÇALVES, T. V. O. A pós-graduação em Ensino de Ciências e Matemática no Brasil: memórias, programas e consolidação da pesquisa na área. São Paulo: ELF, 2014. p. 98-139.

MIRANDA, M. G.; RESENDE, A. C. A. Sobre a pesquisa-ação na educação e as armadilhas do praticismo. Revista Brasileira de Educação, v. 11, n. 33, p. 511-18, 2006.

MOLINA, R.; GARRIDO, E. A produção acadêmica sobre pesquisa-ação em educação no Brasil: mapeamento das dissertações e teses defendidas no período 1966-2002. Formação Docente, v. 2, n. 2, p. 27-40, 2010.

MORIN, A. Pesquisa-ação integral e sistêmica: uma antropopedagogia renovada. Rio de Janeiro: DP\&A, 2004.

SÁNCHES GAMBOA, S. Pesquisa em educação: métodos e epistemologias. Chapecó/SC: Argos, 2007.

TEIXEIRA, P. M. M. Pesquisa em Ensino de Biologia no Brasil (1972-2004): um estudo baseado em dissertações e teses. 2008, Tese (Doutorado em Educação), Universidade Estadual de Campinas, Campinas/SP, 2008.

THIOLLENT, M. Metodologia da pesquisa-ação. São Paulo: Cortez, 2011.

THIOLLENT, M. Notas para o debate sobre pesquisa-ação. In: BRANDÃO, C. R. (Org.). Repensando a pesquisa participante. São Paulo: Brasiliense, 1999. p. 82 - 103.

TRIPP, D. Pesquisa-ação: uma introdução metodológica. Educação e Pesquisa, São Paulo, v. 31, n. 3, p. 443-466, 2005.

TRIVIÑOS, A. N. S. Introdução à pesquisa em Ciências Sociais: a pesquisa qualitativa em educação. São Paulo: Atlas, 1987.

ZEICHNER, K. M. Conferência: O professor reflexivo. In: 20 REUNIÃO ANUAL DA ANPED, 20, 1997. Anais... Caxambú/MG: UFSC/ANPEC, 1997. 
ZEICHNER, K. M. Para além da divisão entre professor pesquisador e pesquisador acadêmico. In: GERALDI, C. M. G.; FIORENTINI, D.; PEREIRA, E. M. A. Cartografias do trabalho docente. Campinas/SP: Mercado de Letras, 1998, p. 207-236.

ZEICHNER, K. M.; DINIZ-PEREIRA, J. E. Pesquisa dos educadores e formação docente voltada para a transformação social. Cadernos de Pesquisa, v. 35, n. 125, p. 63-80, 2005.

\section{SOBRE OS AUTORES}

PAUlO MARCELO M. TEIXEIRA. É licenciado em Ciências Biológicas pela Universidade do Sagrado Coração (USC-Bauru, 1990), e Matemática pela Universidade Estadual Paulista (UNESP, Bauru, 1994), mestre em Educação para a Ciência, pela UNESPBauru, e doutor em Educação, pela Faculdade de Educação da UNICAMP. Pós-Doutorado em Educação, também pela FE/UNICAMP. Foi professor de Ciências, Biologia e Matemática na educação básica entre 1989 e 2000. É Professor Titular do Departamento de Ciências Biológicas e do Programa de Pós-Graduação em Educação Científica e Formação de Professores da Universidade Estadual do Sudoeste da Bahia (UESB). Possui interesse por temáticas associadas a estudos do tipo "Estado da Arte", Educação CTS, Formação de Professores. É editor da Revista de Iniciação à Docência (UESB).

JORGE MEGID NETO. É licenciado em Física pela UNICAMP (1981), mestre em Educação/Ensino de Física (1990) e doutor em Educação/Ensino de Ciências (1999) ambos pela UNICAMP. Foi professor de Física do ensino médio entre 1979 e 1995. Desde 1996 é professor da Faculdade de Educação da UNICAMP. Tem experiência na área de Educação e Formação de Professores, com ênfase no campo da Educação em Ciências e Educação Ambiental, atuando principalmente nos seguintes temas: ensino de ciências, pesquisas do estado da arte, formação inicial e continuada de professores, avaliação de materiais didáticos.

Recebido: 05 de maio de 2017.

Revisado: 25 de julho de 2017.

Aceito: 17 de agosto de 2017. 